Copyright (C) 2011 Inderscience Enterprises Ltd. Access to this work was provided by the University of Maryland, Baltimore County (UMBC) ScholarWorks@UMBC digital repository on the Maryland Shared Open Access (MD-SOAR) platform.

Please provide feedback

Please support the ScholarWorks@UMBC repository by emailing scholarworks-group@umbc.edu and telling us what having access to this work means to you and why it's important to you. Thank you. 


\title{
If you think socialisation in mLearning is difficult, try personalisation
}

\author{
Zane L. Berge \\ University of Maryland, Baltimore County, \\ 1000 Hilltop Circle, \\ Baltimore MD 21250, USA \\ Email: berge@umbc.edu
}

\begin{abstract}
Recently a lot has been written about Web 2.0, its focus on social networking, and its potential for eLearning. This carries forward to mLearning, a particular type of eLearning. Personalised learning has also been in the literature for decades. Much of this has involved a plea to individualise learning based on learning styles theories. This paper reviews the case for personalised learning, but instead of building on learning styles, the case presented here has more to do with mLearning as a way for learners having choice in what, how, and where they learn, both in school and out of school.
\end{abstract}

Keywords: mLearning; mobile learning; organisation; personalised learning; social networking; learning styles; socialisation.

Reference to this paper should be made as follows: Berge, Z.L. (2011) 'If you think socialisation in mLearning is difficult, try personalisation', Int. J. Mobile Learning and Organisation, Vol. 5, Nos. 3/4, pp.231-238.

Biographical notes: Zane L. Berge, $\mathrm{PhD}$, is Professor, and former Director, Training Systems Graduate Program at the University of Maryland, Baltimore County. His teaching and scholarship focuses on distance education, mLearning, and training in the workplace.

\section{Introduction}

Every era of technology has, to some extent, formed education in its own image. In the era of mass print literacy the textbook was the medium of instruction, and a prime goal of the education system was effective transmission of the canons of scholarship. During the computer era of the past fifty years, education has been re-conceptualised around the construction of knowledge through information processing, modelling and interaction. For the era of mobile technology, we may come to conceive of education as conversation in context, enabled by continual interaction through and with personal and mobile technology. (Sharples et al., 2005, paragraph 21)

Recently, a debate has been waged by educators regarding expectations of a new generation of learners - generation Y or Millennials - who are often more tech-savvy than previous generations. The issue is how this generation's expectations should change how teaching is done, or at least how the learning environment should change because of the new tools (Chen et al., 2008). Much of the argument seems to hinge on whether learners who are use to constant social interaction away from school should be able to 
use this modus operandi in their formal, in-school tasks. Socialisation is about people being able to mingle and establish connections on one or more levels. In education, as people socialise, they speak with one another; share ideas and information and confirm the connections made through agreed upon means and language (Irwin and Berge, 2006). Certainly a lot of learning has a social component, and it can be argued that learning through collaboration and during socialisation is at times difficult to orchestrate. Still, connections with other people are what the web and using mobile devices has been all about during the past decade.

This paper reviews the case for personalising learning. Much of that in the past has to do with what is called in the literature, learning styles. But, rather than relying on teaching to a student's learning style(s), the foundation here is on student learning. Online learning and technology-based learning promotes student-centred eLearning, and it could be that mLearning will be used to help develop a learner-centred approach that will increase student positive attitudes, motivation, and engagement during their learning.

Mobile learning, or mLearning (sometimes also called wireless, ubiquitous, pervasive, or nomadic learning), refers in this paper to a type of learning, more specifically a type of eLearning, that uses personal, wireless communication devices as a delivery system for content and support of learning. It is important to note that it is the learner who is mobile, not just the technology. Individualised, or personalised learning adapts to the learner's abilities, knowledge, learning preferences, and supports personal learning. Sharples et al. (2005) suggested four aspects to formulating a theory of mLearning. First, the theory should place mLearning within the context of learning, and also distinguish how it is unique. Secondly, by its nature, the concept of mobile learning indicates that a large part of the learning takes place away from formal classrooms, and therefore a theory of mLearning must embrace a view of informal learning and learning in various venues. Thirdly, Sharples et al. state that a theory of mLearning needs to account for contemporary practice, such as learner-centeredness, knowledge-centeredness, assessmentcenteredness and community-centeredness. Finally, the fourth aspect that a theory of mLearning must take into account is the ubiquitous use of personal, mobile devices. While this paper does not propose a comprehensive theory of mLearning, it does speak to many of the elements Sharples and colleagues suggested.

Personalised learning in the sense it is discussed here, is both a set of customisable tools, and a philosophy that allows both the individual to create an effective learning environment in which the learner is willing to engage, and also a means that results in learning that is personal or relevant to an individual learner. While it may involve formal education, individual learning is characterised by learning just-in-time according to the situation - that is, learning in an authentic context and culture in which the learner is involved. mLearning is evolving into an anytime, anyplace capability for the learner, that uses an unobtrusive set of technologies that is suited to everyday problems, situations, and communication in school and elsewhere (Sharples, 2000; Shih et al., 2010). As it becomes harder to distinguish when and where the need for learning occurs within everyday activities, it becomes necessary for learning capabilities that meet these needs everywhere and anytime on a personal level.

At this point it should be noted that, regarding mLearning can pretty much be thought of as simply one of the latest permutations of distance education. It is probably more important than most others, perhaps because it is in widespread use. This is said as prelude to stating that the biggest problems with distance education will turn out to be the 
biggest problems in education. That is, technologies in any form, in the past, now, or in the future, add a layer of considerations for educators, but in and of itself has little to do with teaching and learning.

So, in some sense, one could do a global search on 'mLearning' in this paper and replace it with 'distance education' without changing the point being made. It really does not matter how the technologies are defined, or if the specific technologies are replaced with others that we know of or that have not been invented or in use to date. The point being made is that mLearning or some other technology in the future will be used to help develop a learner-centred approach that will increase student motivation, engagement with the subject matter, and help increase their positive attitudes (Hwang and Chang, 2011) about their learning.

\section{The case for personalising learning}

Personalising learning is about meeting an individual student's needs, interests, and abilities. This can take on several forms - from identifying unique characteristics of students; to presenting specific content to each student based on his or her needs at the time; to individually assessing, monitoring, and supporting a student's learning progress. A personal learning environment (PLE) includes the technologies, communities, and resources that constitute an individualised learning platform for a learner to use when directing his or her own learning in pursuit of their learning goals. In a formal educational setting, personalised learning is manifested as student-centred and represents a shift away from the model in which students consume information through such venues as the library or a textbook. The move is towards students making connections from a growing group of resources that they select and organise (ELI, 2009).

It is intuitive isn't it? There is something compelling to most teachers about the notion that students learn in different ways, at different speeds and with different levels of effort. It should be useful to study student differences regarding their learning, design and implement different instruction based on these student differences, and thereby improving student achievement and interest in learning. This has led many educators who are interested in individualised instruction to explore learning styles theories. Learning styles theories state that matching students' learning style preferences with educational interventions compatible with those preferences, should be beneficial to the students' academic achievement (Dunn et al., 1995; Lovelace, 2005).

Therefore, personalised learning has often meant teachers trying to customise instruction - educators' attempts at designing individual instruction for a student, based on his or her needs or preferences. Most scholars who promote personalising learning as a way to improve educational achievement, do so in large part by basing their case on the learning styles literature. Further, more recently this has meant using Howard Gardner's theory of multiple intelligences (MI).

However, in the past 30 years, many researchers raise serious doubts about learning styles studies and Gardner's MI theory, both on theoretical and methodological grounds. The debate and research concerning the evidence for improved student achievement due to differential treatment by teachers based on learning styles, teaching styles, and multiple intelligences continues (Cherniss et al., 2006; Gardner and Moran, 2006; Rauscher and Hinton, 2006; Waterhouse, 2006a; Waterhouse, 2006b; Hsieh et al., 2011). At the very least, it is safe to say that learning styles researchers do not all speak with one 
voice (Guldberg, 2004). There is also a case that can be made for other interventions having a greater effect size on student achievement than personalisation, and these other things (e.g. reinforcement, feedback) are what teachers should spend their limited time and resources doing (Walberg, 1984).

\section{A shift from teaching to learning}

The traditional, formal, classroom model requires the instructional designer to design to the 'typical' learner - a learner who does not exist. Informal learning is usually unsystematic, unorganised, and many times unintentional as well. Yet it is informal learning in which a learner is engaged most of his or her lifetime. Informal learning is often the most relevant and therefore most motivated learning that occurs (see, e.g. Swan et al., 2005). Hence, it is not surprising that the formality of the learning is probably the biggest factor that determines whether learning is teacher-led or student-led (Chen et al., 2008). How do educators promote a learning environment that is motivating, relevant, and engaging, perhaps in place of what has heretofore been dominated by the traditional, formal model?

While customisation of teaching is a popular approach to individualisation, personalisation can also be approached in a manner where students have choices and flexibility. In general, at most times in school, students do not have much say in what, when, where, or how they are to learn. Rather than teaching to learning styles, a stronger approach toward personalising learning may be for learners to take into account their own strengths and weaknesses to develop self-direction, self-motivation, and selfassessment of their own learning. The more a student has a say in such matters, the more personalised his or her learning becomes (Berge, 1996).
A reliable and valid instrument which measures learning styles and approaches could be used as a tool to encourage self-development, not only by diagnosing how people learn, but by showing them how to enhance their learning. As Garner (2000) has argued, self-development is more likely to result from increasing learners' knowledge of the relative advantages and weaknesses of different models, than from learners being assigned a particular learning style. (Coffield et al., 2004, p.50)

Learning with new technologies has encouraged a learner-centred approach. The motivation for independent learning is crucial to personalisation. It reduces dependence on the teacher-led, traditional classroom (Hargreaves, 2004). Of course, more student responsibility regarding instruction carries with it more risks in some ways. A student may use poor judgement when making a choice or make a choice that was ill-considered. Giving the student a voice (Storey, 2007) in how he or she will learn also gives the student choice and flexibility and should be tried - not just with regard to the technology to use, but in the teaching approach taken and the learning environment created. ELI (2009) states the implications for personalised learning environments as:

The concept of the PLE marks a fundamental change in the role resources (people and media) play in teaching and learning. In an environment where information is ubiquitous and needs only to be located, there is a greater premium on skills that support fast and accurate access to information and on the ability to assess that information. In this regard, teaching is less a matter of data transmission and more a collaborative exercise in collection, orchestration, remixing, and integration of data into knowledge building. The goal for the 
student shifts from a need to collect information to a need to draw connections from it to acquire it, disseminate it, and collaborate in its use. Furthermore, the use of PLEs may herald a greater emphasis on the role that metacognition plays in learning, enabling students to actively consider and reflect upon the specific tools and resources that lead to a deeper engagement with content to facilitate their learning. (Section 7)

Allowing a student to make more choices about what and how he or she learns carries with it more responsibility and at some level the need to allow that student the opportunity to fail - even if only in some limited ways. Certainly that type of responsibility goes against the political trends of most formal schooling over the past several decades toward no student failure.

\section{4 mLearning and personalisation}

Currently, there are technical challenges to mLearning that include connectivity, short battery life, the mere fact that mLearning requires the user to interact with small devices, and especially the displaying of useful content on small-screen devices (see, e.g. Obisat and Hattab, 2009). There are also several social and educational challenges such as the intrusion of formal education into daily life, the lack of privacy, especially of young learners, from being continually monitored and assessed through their mobile devices, the problem of assessing learning outside the classroom, how to support learning across many contexts, the developing an appropriate theory of learning for the mobile age, and the design of technology to support a lifetime of learning (Eschenbrenner and Nah, 2007). Additionally, current school policies are often problematical to any strategy or practice of individualising mLearning. Current policies are often driven by cultural norms, the value system, and government standardisation, in which such learning would take place. As Facer et al. (2005) noted, "despite the rhetoric of individualised and collaborative learning, [the curriculum] continues to demand a focus on didactic teaching and quantifiable results" (Conclusions, Section 6).

Still, there is potential with mLearning to increase personalised, student-centred learning.

The young people are used to personalized learning through multi-media. People take in information from their environment through the sensory channels, especially through sound, sight, and feeling. A person may have more of an affinity for learning through one sensory mode than through another; thus information presentation and resulting learning are individualized if the person is allowed to function in the sensory learning mode that best suits him rather than one which doesn't.... Sensory bombardment is present in the sense that the information hits the auditory mode (speech and music) and the visual mode, both the sight of the word symbol and of pictorial information. Out of this bombardment, young people take personalized, individualized knowledge. More information is presented through multi-media than through the single visual mode of recognizing word-print symbols-reading. Thus, many people who have been trained on multi-media have difficulty adjusting to the single-medium mode of printed language. Since more information is presented through multi-media modes, the student who is low in verbal skills may have a better chance to acquire information. (Thompson, 1977, p.94) 
What is obvious to even the casual educator and educational researcher is that creating learning environments situated in authentic, real-world problems using a host of resources and technologies cannot be left to chance. Rather, for mLearning to help the individual it must be based on well designed, data-driven learning support systems.

\title{
5 The future of mLearning and personalising learning
}

If Web 2.0 connected people, Web 3.0 will connect machines and is often referred to as the 'semantic network'. Where is mLearning headed in light of the next generations of the Web?

\begin{abstract}
Web 4.0 will, in theory, include an array of sensors that will gather information from one's environment and use them to create a deep profile of your behaviors and activities (Nash, 2008, para. 12). With Web 4.0 and personal software agents that track and register your purchases, your movements, your professional, commercial and recreational activities the future seems to promise a truly brave new world of targeted and meaningful information. Your past behaviors and activities will be considered predictors of future behavior, and the information streamed to you will be based on patterns that you have established. In theory, the information will help you do a better job in whatever you want to do. However, will you be held hostage to your old patterns? Will the information actually restrict your options? (Nash, 2008, para. 1)
\end{abstract}

This has some obvious advantages, especially in the areas of informal learning. Oliver (2008) pointed out that with learning "we might be seeing a situation in which the student progresses along a learning pathway not only influenced by their degree/tutors but also by who they know, their interests, career objectives, progression in particular subjects etc. The risk is that this type of environment may limit learning by more or less repeating and reinforcing a person's existing knowledge". "The ability to branch out and think about obscure, unrelated, even random things can and will be seriously constricted in the world of Web 4.0 as envisioned now" (Nash, 2008, para. 13).

\section{Conclusions}

As technology evolves, personalised devices will be able to profile and store user preferences, user contexts, and information that can be used to deliver a tailored experience to individual learning needs and preferences (Bartolomeo et al., 2008). For such a successful personalised mLearning experience, a model of the learner must be generated and stored which contains a profile of the individual's needs and preferences (Marin and Mohan, 2009).

The point here is that advances in technology will happen. Some of them will be rapid and far-reaching. It is incumbent on educators to work toward helping each individual learn regardless of the stage that technology exists at the time. Mobile technologies are important tools for exploring and finding relevant knowledge, and doing so just-in-time. This will continue to be the case in the foreseeable future. As students live with portable computers, cell phones, and other handheld mobile devices at their side, a challenge becomes deciding how their interaction with these devices can be used for their individual learning so that mLearning promotes personalised opportunities rather than being limited and limiting to their learning. This is a challenge educators should take on without delay. 


\section{References}

Bartolomeo, G., Petersen, F. and Pluke, M. (2008) 'Personalization and user profile management', International Journal of Interactive Mobile Technologies, Vol. 2, No. 4, pp.25-29. Available online at: http://online-journals.org/i-jim/article/view/666/611

Berge, Z.L. (1996) 'Learning styles in the classroom: why change?', Journal of Professional Studies, Vol. 3, No. 2, pp.66-73.

Chen, W.P., Millard, D.E. and Wills, G.B. (2008) 'Mobile VLE vs mobile PLE: how informal is mobile learning?', in mLearn 2008 Conference, 8-10 October, The University of Wolverhampton. Available online at: http://eprints.ecs.soton.ac.uk/16158/1/ InformalMobileLearning_modification_final_0718.pdf

Cherniss, C., Extein, M., Goleman, D. and Weissberg, R.P. (2006) 'Emotional intelligence: what does the research really indicate?', Educational Psychologist, Vol. 41, pp.239-245.

Coffield, F., Moseley, D., Hall, E. and Ecclestone, K. (2004) 'Should we be using learning styles? What research has to say to practice', Learning and Skills Research Centre, London. Available online at: http://www.lsda.org.uk/files/pdf/1540.pdf

Dunn, R.S., Griggs, S.A., Gorman, B.S., Olson, J.E. and Beasley, T.M. (1995) 'A meta-analytic validation of the Dunn \& Dunn model of learning-style preferences', Journal of Educational Research, Vol. 88, pp.353-362.

ELI (Educause Learning Initiative) (2009, May) 7 things you should know about personalized learning environments. Available online at: http://net.educause.edu/ir/library/pdf/ELI7049.pdf

Eschenbrenner, B. and Nah, F.F-H. (2007) 'Mobile technology in education: uses and benefits', International Journal of Mobile Learning and Organisation, Vol. 1, No. 2, pp.159-183.

Facer, K., Faux, F. and McFarlane, A. (2005) 'Challenges and opportunities: making mobile learning a reality in schools', Proceedings of the 4th World Conference on mLearning. Available online at: http://www.mlearn.org.za/CD/papers/Facer\%20-\%20Faux\%20-\%20 McFarlane.pdf

Gardner, H. and Moran, S. (2006) 'The science of multiple intelligences theory: a response to Lynn Waterhouse', Educational Psychologist, Vol. 41, No. 4, pp.227-232.

Garner, I. (2000) 'Problems and inconsistencies with Kolb's learning styles', Educational Psychology, Vol. 20, No. 3, pp.341-348.

Guldberg, H. (2004, July 21) "Class divisions: who benefits from the "personalised learning" strategy of dividing school pupils into sub-sets?', Spiked. Available online at: http://www.spiked-online.com/index.php?/site/article/2329/

Hargreaves, D. (2004, October) Personalizing learning: The next steps in working laterally, International Network for Educational Transformation. Available online at: http://www.sstinet.com.au/files/David_Hargreave_-_Personalising_Learning_1_-_next_steps.pdf (accessed on 23 May 2009).

Hsieh, S.W., Jang, Y.R., Hwang, G.J. and Chen, N.S. (2011) 'Effects of teaching and learning styles on students' reflection levels for ubiquitous learning', Computers \& Education, Vol. 57, No. 1, pp.1194-1201.

Hwang, G.J. and Chang, H.F. (2011) 'A formative assessment-based mobile learning approach to improving the learning attitudes and achievements of students', Computers \& Education, Vol. 56, No. 1, pp.1023-1031.

Irwin, C. and Berge, Z.L. (2006, March) 'Socialization in the online classroom', e-Journal of Instructional Science and Technology, Vol. 9, No. 1. Available online at: http://www.usq.edu.au/electpub/e-jist/docs/vol9_no1/papers/full_papers/irwin_berge.htm

Lovelace, M.K. (2005, January/February) 'Meta-analysis of experimental research based on the Dunn and Dunn Model', The Journal of Educational Research, Vol. 98, No. 3, pp.176-183.

Marin, D. and Mohan, P. (2009) 'Personalization in mobile learning', International Journal of Mobile Learning and Organisation, Vol. 3, No. 1, pp.25-43. 
Nash, S.S. (2008, 13 October) Web 3.0, Web 4.0 and personal agents: Will they open or restrict choice? Available online at: http://elearnqueen.blogspot.com/2008/10/web-30-web-40-andpersonal-agents-will.html

Obisat, F. and Hattab, E. (2009) 'A proposed model for individualized learning through mobile technologies', International Journal of Computers, Vol. 1, No. 3, pp.125-135. Available online at: http://www.naun.org/journals/computers/ijcomputers-111.pdf

Oliver, A. (2008, 17 October) 'Where are we going? Let's talk about Web 3.0 and Web 4.', e-Learning Now. Available online at: http://drandyoliver.edublogs.org/2008/10/17/where-arewe-going-let $\% \mathrm{e} 2 \% 80 \% 99$ s-talk-about-web-30-and-web-40/

Rauscher, F.H. and Hinton, S.C. (2006) 'The Mozart effect: music listening is not music instruction', Educational Psychologist, Vol. 41, No. 4, pp.233-238. Available online at: http://www.uwosh.edu/departments/psychology/rauscher/Ed\%20Psych.pdf

Sharples, M. (2000) 'The design of personal mobile technologies for lifelong learning', Computers \& Education, Vol. 34, pp.177-193. Available online at: http://www.eee.bham.ac.uk/ sharplem/papers/handler\%20comped.pdf

Sharples, M., Taylor, J. and Vavoula, G. (2005) 'Towards a theory of mobile learning', Paper presented in the Proceedings of the 4th World Conference on Mlearning (MLearning 2005), SA, 25-28 October. Available online at: http://www.mlearn.org.za/CD/papers/Sharples\%20Theory\%20of\%20Mobile.pdf

Shih, J.L., Chuang, C.W. and Hwang, G.J. (2010) 'An inquiry-based mobile learning approach to enhancing social science learning effectiveness', Educational Technology \& Society, Vol. 13, No. 4, pp.50-62.

Storey, V. (2007) 'Recentering American education on the student: personalization of learning', Values and Ethics in Educational Administration, Vol. 5, No. 4, pp.1-8. Available online at: http://www.ed.psu.edu/uceacsle/VEEA/VEEA_Vol5Num4.pdf

Swan, K., van't Hooft, M., Kratcoski, A. and Unger, D. (2005) 'Uses and effects of mobile computing devices in K-8 classrooms', Journal of Research on Technology in Education, Vol. 38, pp.99-112. Available online at: http://www.iste.org/Content/NavigationMenu/ EducatorResources/YourLearningJourney/InnovativeLearningTechnologies/mobile.pdf

Thompson, N.C. (1977, April). 'Some ideas on how English teachers can develop an expertise in multi-media', English Journal, Vol. 66, No. 4, pp.92-95. Available online at: http://www. jstor.org/stable/814984

Walberg, H.J. (1984, May) 'Improving the productivity of American schools', Educational Leadership, Vol. 41, No. 8, pp.19-27.

Waterhouse, L. (2006a) 'Multiple intelligences, the Mozart effect, and emotional intelligence: a critical review', Educational Psychologist, Vol. 41, No. 4, pp.207-225.

Waterhouse, L. (2006b) 'Inadequate evidence for multiple intelligences, Mozart effect, and emotional intelligence theories', Educational Psychologist, Vol. 41, No. 4, pp.247-255. 